\title{
Anti-idiotype-mediated epitope spreading and diminished phagocytosis by a human monoclonal antibody recognizing late-stage apoptotic cells
}

\author{
R Gandhi ${ }^{1,2}$, E Hussain ${ }^{2}$, J Das ${ }^{1}, \mathrm{R}$ Handa $^{3}$ and R Pal ${ }^{*, 1}$ \\ 1 Immunoendocrinology Lab, National Institute of Immunology, Aruna Asaf Ali \\ Marg, New Delhi, India \\ 2 Department of Biosciences, Jamia Millia Islamia, Maulana Mohammed Ali \\ Jauhar Marg, New Delhi, India \\ ${ }^{3}$ Department of Medicine, All India Institute of Medical Sciences, Ansari Nagar, \\ New Delhi, India \\ * Corresponding author: R Pal, Immunoendocrinology Lab, National Institute of \\ Immunology, Aruna Asaf Ali Marg, JNU Complex, New Delhi. \\ Tel: +91 11 26703787; Fax: + 9111 26162125; E-mail: rahul@ nii.res.in
}

Received 08.3.05; revised 05.12.05; accepted 21.12.05; published online 10.2.06 Edited by M Hengartner

\begin{abstract}
Apoptotic cells are considered an important auto-antigenic source in diseases such as systemic lupus erythematosus (SLE). A human monoclonal antibody demonstrating exquisite specificity towards late-stage apoptotic cells was generated from an SLE patient. Polyreactive recognition of ribonucleoproteins Ro52 and Ro60 was observed. The antibody significantly diminished the phagocytosis of apoptotic cells and a concomitant decrease in transforming growth factor- $\beta$ (TGF- $\beta$ ) secretion was observed. Light and heavy chain sequencing revealed the antibody to be in essentially germline configuration. Elicited anti-idiotypic antibodies bound distinct self-antigens and showed augmented reactivity towards apoptotic cells as well. Thus, near-germline encoded antibodies recognizing antigens externalized during the process of apoptosis can mediate a variety of potentially pathogenic effects; decreases in the phagocytic uptake of dying cells would constitute a disease-perpetuating event and stimulation of the idiotypic network could lead to intermolecular epitope spreading, increasing the range of molecular targets.

Cell Death and Differentiation, (2006) 13, 1715-1726. doi:10.1038/sj.cdd.4401866; published online 10 February 2006
\end{abstract}

Keywords: autoimmunity; systemic lupus erythematosus; antibody diversification

Abbreviations: ACAMPs, apoptotic cell-associated molecular patterns; dsDNA, double-stranded DNA; SLE, systemic lupus erythematosus; TFG- $\beta$, transforming growth factor- $\beta$; TNF- $\alpha$, tumor necrosis factor- $\alpha$

\section{Introduction}

It is increasingly recognized that reactivity towards 'self' is not an uncommon event. Anti-self responses can be readily elicited either upon deliberate immunization or in association with responses to non-self antigens. In most instances however, such reactivity does not result in pathogenesis. In susceptible individuals, systemic autoimmunity results in the generation of humoral responses against a wide variety of targets. More than a hundred autoantibody specificities have been documented in subjects of SLE (a prototypic non-organspecific autoimmune disease), which include reactivity towards proteins, lipids and nucleic acids. ${ }^{1,2}$ In some instances, it has been possible to establish correlation between the presence of antibodies of a particular specificity and distinctive pathology; for example, many reports describe the association of anti-double-stranded DNA(dsDNA) antibodies and kidney pathology, ${ }^{3}$ and maternal anti-Ro and anti-La antibodies have been associated with neonatal lupus and congenital heart block. ${ }^{4}$

The phenomenon of apoptosis, central to the development and differentiation of all organs, has been implicated in SLE pathogenesis. In humans, an increased rate of apoptosis has been observed in peripheral blood cells of SLE patients. ${ }^{5}$ It has been established that several autoantigens are externalized to bleb-like structures when cells die, possibly gaining initial access to the immune system. ${ }^{6}$ Evidence has been gathered for the immunogenecity of apoptotic debris; systemic exposure of mice to apoptotic cells bearing blebs induces autoantibody production, ${ }^{7}$ and an SLE-like phenotype results when individual components that aid in the clearance of apoptotic debris are genetically deleted. ${ }^{8-10}$

Antibodies of the IgM isotype dominate primary immune responses. Interestingly, serum IgM knockout animals demonstrate an SLE-like phenotype, ${ }^{11}$ and some components of 'natural' IgM antibodies have been shown to bind apoptotic cells and may play an important role in clearance of cellular debris. $^{12}$ This study was conceived to investigate the physiological significance and immunological consequences of an early human autoimmune response specifically directed against apoptotic cells. Towards this end, an IgM $[\kappa]$ human monoclonal antibody specific to cell antigen(s) revealed at the late stages of apoptosis was generated from B cells isolated from an SLE patient. A second antibody of the same isotype, nondiscriminatory between healthy and apoptotic cells, was also generated and was employed as control. The antibodies were characterized for cellular and antigenic specificity. The phagocytosis of apoptotic cells is normally an efficient and noninflammatory process; the relative influence of the two antibodies on this event was assessed in terms of both efficacy and the secretion of cytokines. Studies by other investigators have shown that immunization with 'pathogenic idiotypes', such as the public idiotype 16/6 (found on many mouse and human anti-DNA antibodies), can induce a lupuslike pathology. ${ }^{13}$ The consequences of an anti-idiotypic response with regard to ribonucleoprotein antigens (polyreactive recognition of which was demonstrated by the 
apoptotic cell specific antibody, as described below) has not been widely explored but is clearly relevant, given the macromolecular nature of the complexes in which these proteins exist. Anti-idiotypic antibodies, generated by immunization of rats with the apoptotic cell specific antibody, were characterized for cellular and antigenic reactivity.

\section{Results}

\section{FACS and immunofluorescence}

Since cell death is a perpetual and ongoing phenomenon in cultured cells, antibodies specifically targeted at apoptotic (or dead) cells would be expected to recognize a minor subpopulation of such cells. Initial FACS analysis was therefore designed to detect such reactivity. In addition, antibodies that exhibited frank recognition of all cells in culture (signifying nondiscriminatory recognition of healthy as well as dying cells) were also scored for. As indicated, two antibodies (RN86, specifically reactive towards late-stage apoptotic cells, and PR5, nondiscriminatory between healthy and apoptotic cells) were generated.

Figure 1 (empty profiles) shows the reactivity of the RN86 and PR5 with MOLT-4 cells. The filled profiles indicate negative controls (staining obtained in the presence of secondary reagent alone). RN86 consistently recognized between 5 and $10 \%$ of nonpermeabilized MOLT-4 cells in culture (arrow in top left panel, Figure 1a), whereas PR5 demonstrated cell surface recognition of all cells (Figure $1 \mathrm{~b}$, top right panel). While cell permeabilization did not significantly alter PR5 reactivity (Figure 1a, bottom right panel), it resulted in the recognition of all cells by RN86 (Figure 1a, bottom left panel). For both antibodies, similar profiles were observed upon human cell lines of many different lineages, indicating recognition of ubiquitous antigens(s) (data not shown).

To confirm that RN86 was indeed specifically directed at apoptotic cells, apoptosis was induced by addition of camptothecin to the culture. Figure $1 \mathrm{~b}$ shows a two-color FACS profile, with RN86 antibody staining on the $X$-axis and annexin- $V$ staining on the $Y$-axis. As is apparent from the figure, the antibody demonstrated exquisite specificity towards annexin-V positive (i.e. apoptotic) cells. Some cells that were reactive towards annexin- $\mathrm{V}$, however, were nonreactive towards antibody (Figure 1b, top left quadrant). To ascertain if this could be a result of temporal difference during apoptosis induction, the kinetics of appearance of RN86 reactivity was studied in relation to other markers of cell death. Antibody positivity occurred after annexin- $V$ binding (i.e., after the exposure of phosphotidylserine (PS)), and paralleled reactivity towards PI (Figure 1c). The fact that cells continued to exclude trypan blue precluded the possibility that membrane porosity had increased to an extent that cytoplasmic antigens were being recognized in this experiment. Similar results were obtained when UV light or $\mathrm{H}_{2} \mathrm{O}_{2}$ was used for the induction of apoptosis; in addition, RN86 demonstrated similar specificity towards mouse thymocytes induced to undergo apoptosis by treatment with dexamethasone (data not shown), indicating evolutionary conservation of the antigen(s). a
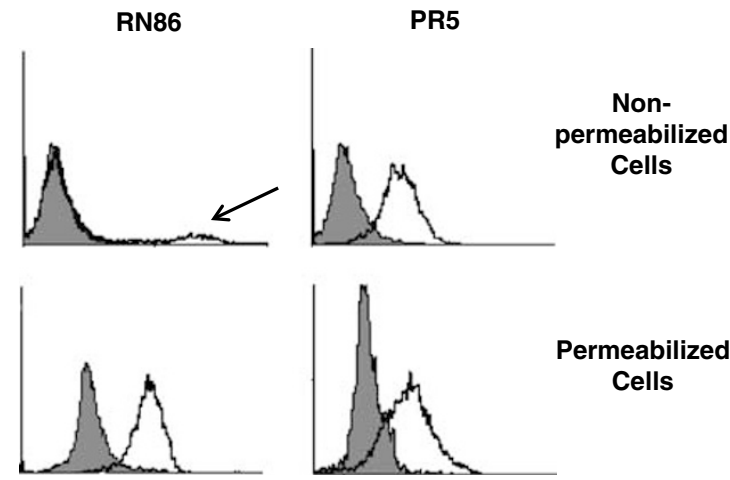

b

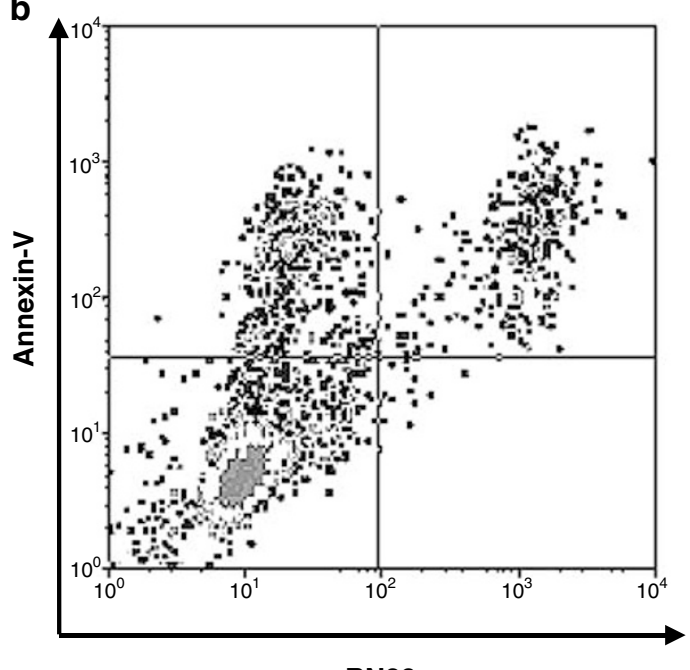

RN86

C

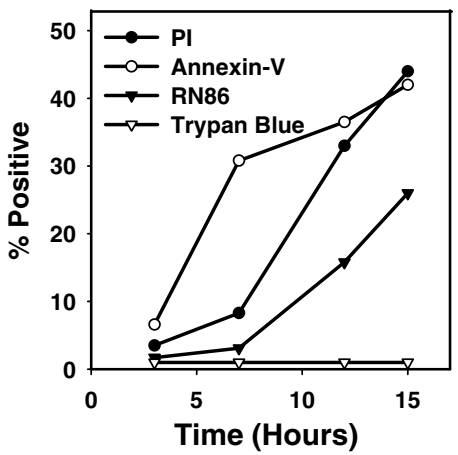

Figure 1 (a) FACS reactivity of RN86 and PR5 upon nonpermeabilized and permeabilized MOLT-4 cells. Filled profiles indicate negative controls, whereas antibody reactivity is plotted as empty profiles. RN86 recognized a subpopulation of nonpermeabilized cells, as demarcated by the arrow; all permeabilized cells were recognized. PR5 did not distinguish between the two cell preparations. (b) Dual-color FACS analysis of RN86 upon apoptotic cells. $X$-axis shows antibody reactivity and $Y$-axis annexin- $V$ binding. (c) Kinetics of the appearance of RN86 reactivity in relation to other markers of cell death during apoptosis, indicating relatively late appearance of reactive antigen(s) on the cell surface

Immunofluorescence assays supported the data on RN86 reactivity. The lack of recognition of healthy, nonpermeabilized cells by RN86 is depicted in Figure 2a; the phase contrast image is shown on the left. Binding to permeabilized cells was apparent (Figure 2b); all cells were stained. These 

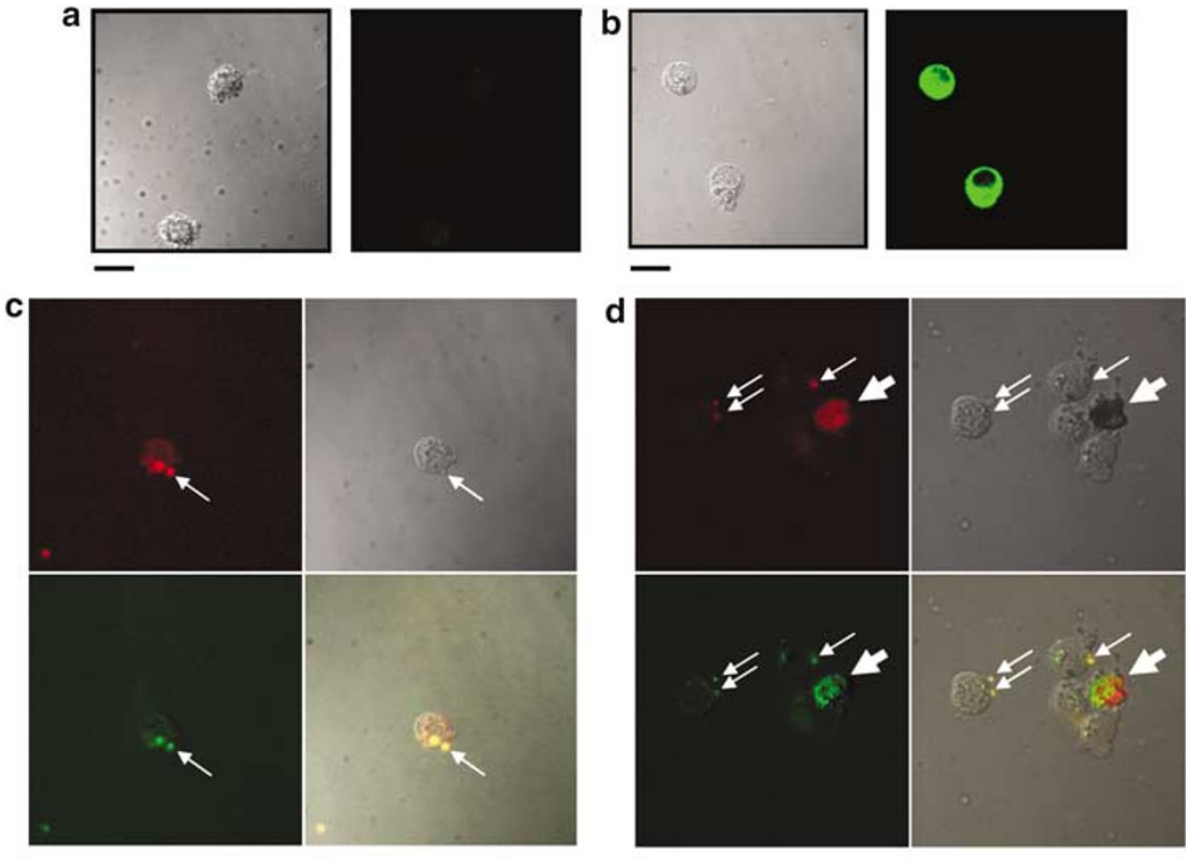

Figure 2 Cellular reactivity of RN86. (a) Immunofluorescence analysis on nonpermeabilized and (b) permeabilized Jurkat cells. Phase contrast images are shown on the left in each case. No binding was observed on nonpermeabilized cells whereas on permeabilized cells, significant cytoplasmic localization was observed. (c, d) Recognition of cell surface blebs on apoptotic cells by RN86. Top right, phase contrast; top left, PI; bottom left, RN86; bottom right, colocalization image. Thin arrows point to surface protrusions. The thick arrow in (d) points to a lysed cell, indicating internalization of both PI and RN86. Bars, $10 \mu \mathrm{m}$

data reiterate the fact that the antibody recognized a cytoplasmic antigen, and did not recognize the surface of healthy cells. Figure $2 \mathrm{c}$ demonstrates binding of RN86 on the surface of late-stage apoptotic cells; the phase contrast images are depicted on the top right; the arrow demarcates a surface protrusion or bleb. The antibody (bottom left, green) and $\mathrm{PI}$ (top left, red) colocalized upon the same discrete areas on the cell surface (seen as yellow, bottom right). Similarly, recognition of several incipient blebs which bound both antibody and $\mathrm{PI}$ is also apparent in Figure $2 \mathrm{~d}$, some of which have been demarcated by the arrows; in both Figure $2 \mathrm{c}$ and $\mathrm{d}$, other areas of the cell membrane remained relatively unbound by both RN86 and PI, further reiterating antibody specificity. Figure 2d also depicts a lysed cell (indicated by the thick arrow), which acts as an additional index of antibody specificity; as expected, both PI and RN86 bound internal components.

Parallels in the kinetics of RN86 antibody and PI reactivity (Figure 1c), as well as the colocalization of PI and RN86 upon the surface of late-stage apoptotic cells (Figure $2 c$ and $d$ ) prompted us to study if the antibody exclusively bound PI-positive cells. Figure 3 depicts FACS analysis of RN86 and $\mathrm{PI}$ upon control and late-stage (15 h) apoptotic cells. It was apparent that only cells that bound $\mathrm{PI}$ were recognized by antibody. Interestingly, at both time-points (as well as at intermediate points of observation, not shown), there existed cells that bound $\mathrm{PI}$ and not antibody. This observation further re-iterates that $\mathrm{PI}$ positivity does not automatically imply that the permeability of the cellular membrane has increased to an extent that antibody has unrestricted access to cellular antigens. Differential gating indicated that in cultures of a
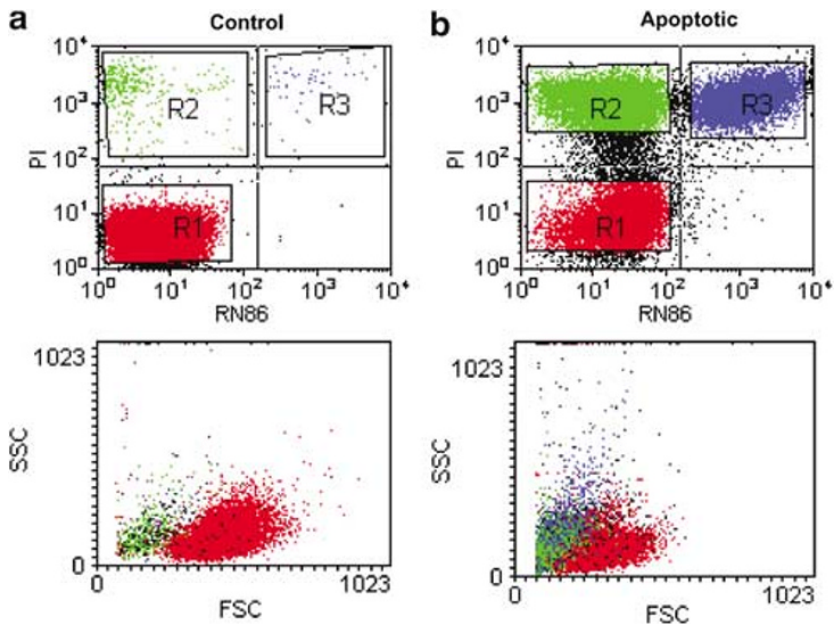

Figure 3 Two-colour FACS analysis of RN86 and PI reactivity. (a) Control cultures; (b) cultures at $15 \mathrm{~h}$ post-apoptosis induction. In both instances, bottom panels indicate FSC/SSC dot plots of all events, which have been differentially gated on regions $\mathrm{R} 1, \mathrm{R} 2, \mathrm{R} 3$ (in the top panels) and colour-coded for clarity

'healthy', control cells (which exhibited 1-3\% PI positivity) and in cultures of cells post-apoptosis induction, cells staining for $\mathrm{PI}$ alone as well as those dual-staining for $\mathrm{PI}$ as well as RN86 exhibited essentially overlapping (relatively high side scatter and low forward) scatter properties, in marked contrast to the scatter observed for healthy cells, which bound neither $\mathrm{PI}$ or RN86 (Figure 3).

In conclusion, while PR5 recognized antigen(s) present on the surface of healthy cells, RN86 reactivity was confined to 
antigen(s) present in the cytoplasm of such cells, which were translocated to the cell surface during a relatively late stage of apoptosis.

\section{Antigen analysis}

Western blots were conducted to ascertain molecular weights of the antigens recognized by RN86. Figure 4a shows results on lysates derived from two cell lines (HuT-78, human T; Raji, human $\mathrm{B}$ ). The antibody appeared to be reactive towards antigens in the $50-75 \mathrm{kDa}$ range. Similar results were obtained on several other cell lines tested, and upon peripheral human cells (data not shown). Thus, though the antibody was monoclonal in nature, it demonstrated a degenerate recognition pattern. Such multi-reactivity is not uncommon among monoclonal antibodies, especially of the IgM isotype. Significantly however, the degree of degeneracy was extremely restricted.

A panel of recombinant autoantigens was then employed to further discern the specificity of RN86. In consonance with Western blot data, preferential reactivity towards the ribonucleoproteins Ro60 and Ro52 was observed (Figure 4b, top panel). Even though the antibody was derived from hybrids which had been repeatedly subcloned (thereby almost precluding polyclonality), crossreactivity was formally established by absorption experiments. Incubation of RN86 with either Ro60 (Figure 4b, middle panel) or Ro52 (Figure 4b, bottom panel) liganded Sepharose beads significantly inhibited reactivity towards both the corresponding as well as the complimentary antigen. Control preincubations with SmD liganded beads had no significant inhibitory effects (data not

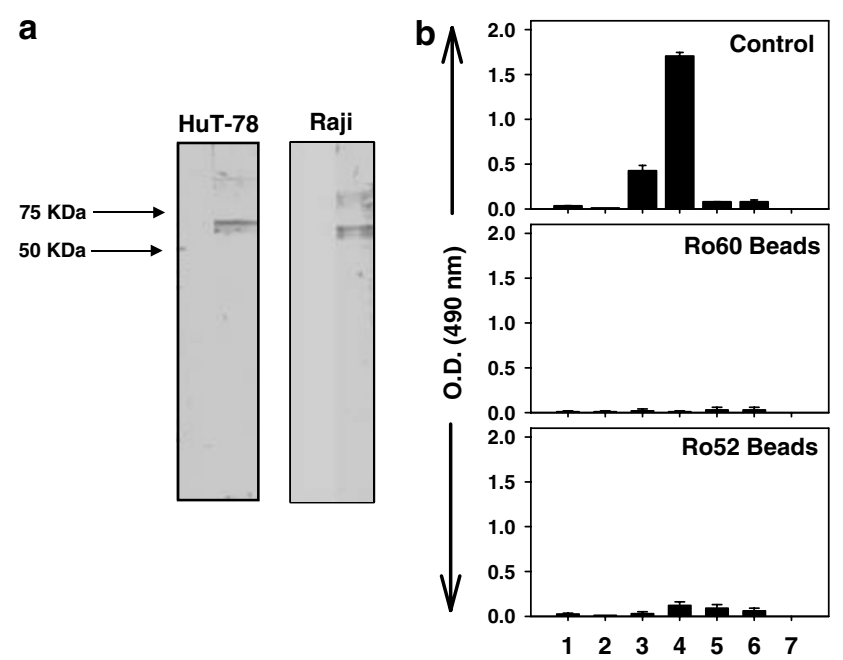

Figure 4 Antigenic reactivity of RN86. (a) Western blot analysis of RN86 reactivity on HuT-78 and Raji cell lysates. Lanes on the left in each case indicate negative controls. The antibody predominantly recognized a protein 'doublet' between 50 and $75 \mathrm{kDa}$. (b) Top panel: ELISA reactivity of RN86 upon recombinant autoantigens after adsorption with control (nonliganded) beads; Middle panel: ELISA reactivity of RN86 upon recombinant autoantigens after adsorption with Ro60-liganded beads; Bottom panel: ELISA reactivity of RN86 upon recombinant autoantigens after adsorption with Ro52-liganded beads. 1: U1 RNP A; 2: SmD; 3: Ro60, 4: Ro52; 5: La; 6: U-1 RNP $70 \mathrm{kDa} ; 7$ : SmB. Arithmetic means and standard errors are shown. RN86 recognized Ro60 and Ro52 in a crossreactive fashion shown). RN86 was nonreactive towards tetanus toxoid, bovine serum albumin, casein, actin, myosin and rabbit IgG and human IgG or IgM. In addition, a lack of reactivity was observed towards cell surface-associated structures of human and mouse peripheral blood mononuclear cells, and towards established cell lines of a wide variety of different cell lineages from both species; minor reactivity towards dsDNA was observed (data not shown). Thus, an apoptotic cellspecific human monoclonal antibody, obtained from an SLE patient, demonstrated crossreactive recognition towards two prominent ribonucleoprotein autoantigens that appear on the surface of dying cells.

Experiments were then conducted to ascertain whether the antigenic sites recognized by the human monoclonal antibody RN86 upon Ro60 and Ro52 were also commonly targeted in patients of SLE. Figure 5a shows the results of direct binding ELISA upon Ro60 of nine sera obtained from SLE patients (black lines) and nine normal human sera (red lines). Three SLE sera were significantly reactive, with two more demonstrating intermediate reactivity, while the others were reactive to essentially the same extent as normal human sera. Such a spectrum of reactivity was along expected lines. In competition assays, all SLE sera without exception significantly reduced the binding of biotinylated RN86 to Ro60. While seven of nine normal sera were ineffective in causing inhibition, two sera could do so (Figure 5b), and the reason for this observation is at present unclear; normal human sera has been shown to exhibit anti-Ro60 reactivity, and the two inhibiting sera were among the highest reactors in the control group. The competitive ELISA thus appeared to indicate no false negatives, but did show a $22 \%$ false-positive rate. The fact that some SLE sera of equivalently low anti-Ro60 titer as normal human sera were by and large more efficient at causing inhibition in the binding of RN86 to Ro60 may be indicative of the fact that RN86 binds to a diseasespecific epitope on the molecule. These data need validation and confirmation upon a larger sample size. Four SLE sera exhibited significantly higher anti-Ro52 titers than did normal human sera (Figure $5 \mathrm{c}$ ). Competitive ELISAs, while generally indicating enhanced suppression of RN86 binding to Ro52 by SLE sera in comparison with normal human sera, did not result in as clear a discrimination between the two groups as seen for Ro60 reactivity, possibly indicating recognition of a relatively uncommon epitope upon Ro52 by RN86 (Figure 5d).

\section{$\mathrm{V}$ region analysis}

Genetic analysis of the antibody was carried out to ascertain $\mathrm{V}$ region usage and to investigate whether the presence of somatic mutations was required for anti-apoptotic cell specificity. Codons were enumerated as per convention. ${ }^{19}$

The nucleotide sequence of the light-chain variable region of RN86 is shown in Figure 6a, and the derived amino-acid sequence in Figure 6b. Comparisons with the closest germline gene segments are shown, with homologies indicated as dots. $V_{\kappa}$ l was utilized (with 012 being the closest germline gene) and $J_{\kappa} 1$ was employed. A single mutation ( $C$ to $T$ ) was observed at codon number 46 (FRW2, Figure 6c). A threebase (TCC) deletion was observed at the end of the 012 

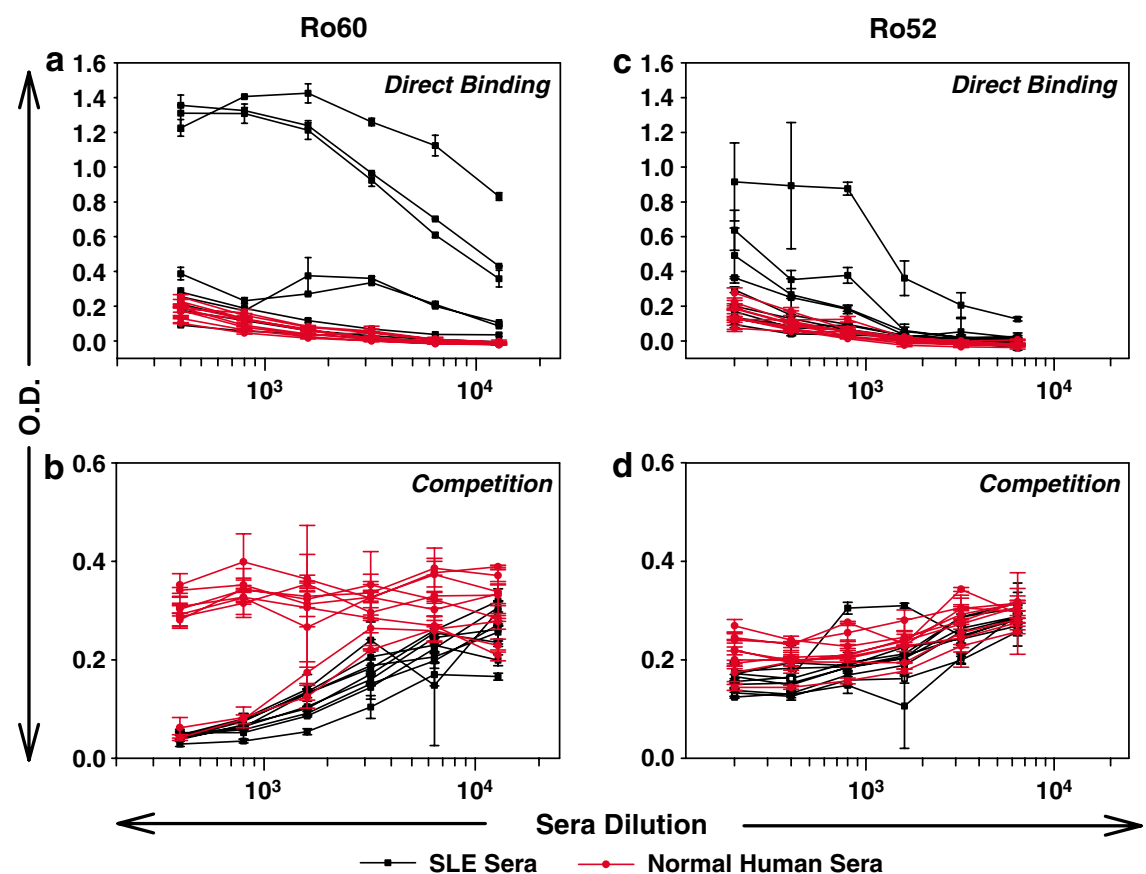

Figure 5 Reactivity of SLE sera (black lines) and normal human sera (red lines) by ELISA. Each point depicts arithmetic means and standard errors. (a) Direct binding analysis of anti-Ro60 reactivity. (b) Analysis of competition between biotin-labeled RN86 and the sera for binding to Ro60. (c) Direct binding analysis of anti-Ro52 reactivity. (d) Analysis of competition between biotin-labeled RN86 and the sera for binding to R052

germline gene (italics, Figure $6 \mathrm{~d}$ ). In addition, a mutation ( $\mathrm{T}$ to A) was seen at codon $96(\mathrm{~J} \kappa 1)$. Mutations at both codon 46 and codon 96 resulted in amino-acid replacements ( $L$ to $F$ and $\mathrm{W}$ to $\mathrm{R}$, respectively, Figure $6 \mathrm{c}$ and $\mathrm{d}$ ).

The nucleotide sequence of the heavy-chain variable region of $\mathrm{RN} 86$ is shown in Figure $7 \mathrm{a}$ and the derived amino-acid sequence in Figure $7 \mathrm{~b}$. The VH3 family was employed, with 53 being the closest germline gene; the entire gene was used, without deletion. Isolated mutations were observed at codon 12 (FRW1), codon 72 (FRW3) and codon 84 (FRW3) (Figure 7c). Four nontemplated bases (TTTG) appeared to be added at the $\mathrm{V}-\mathrm{D}$ junction (underlined font, Figure 7d). The D3-10 segment was used (in Reading Frame 2), with what appeared to be a 10-nucleotide (GTATTACTAT) deletion at its $5^{\prime}$ end and a two-nucleotide deletion (AC) at its $3^{\prime}$ end (italics, Figure 7d). Four nontemplated bases (TGGG) were observed at the D-J junction (underlined font, Figure $7 \mathrm{~d}$ ). $\mathrm{JH} 6$ was employed, possibly with a four-base (ATTA) deletion from its $5^{\prime}$ end (italics, Figure $7 d$ ). Mutations at codons 12 and 72 resulted in amino-acid modification ( $\mathrm{I}$ to $\mathrm{V}$ and $\mathrm{D}$ to $\mathrm{H}$, respectively, Figure $7 \mathrm{c}$ ). An additional mutation from $\mathrm{N}$ to $\mathrm{M}$ was observed in the D3-10 segment, possibly as a result of junctional variations (Figure $7 \mathrm{~d}$ ).

Thus, though neither the heavy- nor light-chain amino-acid sequences of the apoptotic cell-specific antibody RN86 exhibited significant somatic mutations (and observed changes could possibly be the result of allelic variations), many junctional modifications were observed. PR5, on the other hand, did appear to have a somatically mutated heavy chain (data not shown), despite the fact that it too was of an IgM isotype.

\section{Phagocytosis}

The natural fate of apoptotic cells in vivo is phagocytosis. Although a host of ligand-receptor pairs have been implicated in the phagocytic process, the exposure of PS and its recognition by molecules on the phagocyte plasma membrane is considered a seminal event. ${ }^{20}$ Since the antigens recognized by the apoptotic cell specific monoclonal antibody RN86 (Ro52 and Ro60) constitute apoptotic cell-associated molecular patterns (ACAMPs), the influence of the antibody upon the phagocytosis of apoptotic cells was investigated. Addition of the apoptosis-specific antibody RN86 to cultures significantly suppressed the number of phagocytosed apoptotic cells (Figure $\left.8 \mathrm{a},{ }^{*} P=0.003\right)$. PR5, the IgM $(\kappa)$ human monoclonal antibody that was nondiscriminatory between healthy and apoptotic cells, had no such effects, and there therefore existed a significant difference between the inhibitory effects of the two antibodies (Figure $8 a,{ }^{\star \star} P=0.003$ ). These results indicated that antibodies of the IgM isotype which recognized membrane-associated products of cell death could mediate a specific decrease in the phagocytic clearance of apoptotic cells. Supernatants generated from the phagocytosis assays were analyzed to determine the influence of the antibodies upon two key cytokines, TGF- $\beta$ and TNF- $\alpha$; the phagocytosis of apoptotic cells is known to induce the release of the former, while suppressing the release of the latter. ${ }^{21}$ RN86 caused a significant reduction in TGF- $\beta$ levels over controls (Figure $8 \mathrm{~b},{ }^{\star} P=0.0002$ ), as did PR5 (Figure 8b, ${ }^{\star \star \star} P=0.0009$ ). In addition, TGF- $\beta$ levels in RN86-containing cultures were significantly lower (Figure $8 \mathrm{~b},{ }^{* \star} P=0.0004$ ) than in PR5-containing cultures. Notably, decreased TGF- $\beta$ secretion in the presence of RN86 or PR5 was associated with 
a FRW1

GACATCCAGATGACCCAGTCTCCATCCTCCCTGTCTGCATCTGTAGGAGACAGAGTCACCATCACTTGC

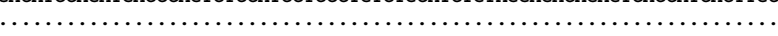

CDR1

FRW2

CGGGCAAGTCAGAGCATTAGCAGCTATTTAAAT TGGTATCAGCAGAAACCAGGGAAAGCCCCTAA

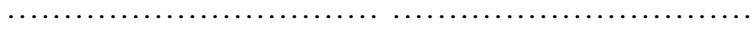

CDR2

FRW3

GTTCCTGATCTAT GCTGCATCCAGTTTGCAAAGT GGGTCCCATCAAGGTTCAGTGGCAGTGGATC

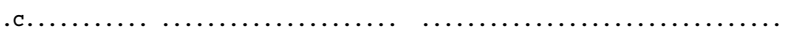

TGGGACAGATTTCACTCTCACCATCAGCAGTCTGCAACCTGAAGATTTTGCAACTTACTACTGT

CDR3

FRW4

CAACAGAGTTACAGTACCCCGAGGACG TTCGGCCAAGGGACCAAGGTGGAATCAAAC

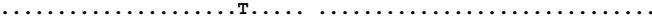

b

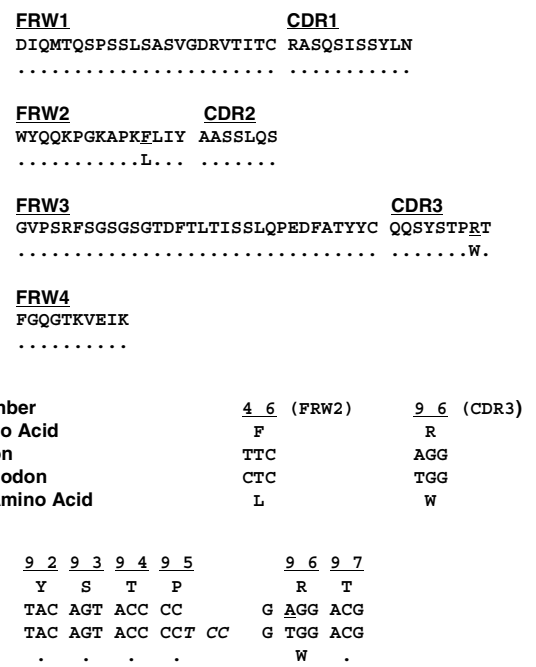

Figure 6 RN86 light-chain (a) nucleotide and (b) derived amino-acid sequence. The 012 germline gene (belonging to the $V_{\kappa} 1$ family) was used along with the $\mathrm{J} \kappa 1$ segment. Identical bases in the germline are indicated as dots and substitutions in the RN86 sequences are underlined. (c) The codon numbers, encoded amino acids and codons corresponding to the two mutations (both replacement) in RN86 are indicated, in comparison with the germline sequences. (d) Depiction of the $\mathrm{V}-\mathrm{J}$ junction. RN86 encoded nucleotides and amino acids are shown, alongside the germline sequences. Dots correspond to conserved amino acids and the single mutated base in RN86 is underlined. A three base pair (TCC, in italics) deletion was observed at the junction. EMBL accession number: AJ548508

an increase in the production of TNF- $\alpha$ compared with controls (Figure 8c). Though, for RN86, levels were not significantly different over controls, PR5 significantly $\left({ }^{\star \star} P=0.0004\right)$ enhanced TNF- $\alpha$ release, even though the antibody did not affect apoptotic cell uptake (Figure 8a). Thus, though the antibodies differed in terms of their effects on the phagocytosis of apoptotic cells, both induced the generation of a typical proinflammatory cytokine milieu.

\section{Anti-idiotypic antibody responses}

One of the autoantigens recognized by the human monoclonal antibody RN86 (Ro60) is known to exist as a component of a macromolecular cytoplasmic complex with another autoantigenic ribonucleoprotein ( $\mathrm{La}$, a protein not recognized by RN86). Since the network theory postulates that 'internal image' idiotypic antibodies can mimic the original antigen, it was hypothesized that immunization with RN86 could lead to a

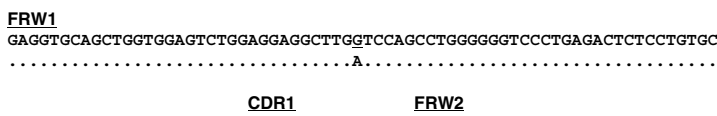

AGCCTCTGGGTTCACCGTCAGT $\frac{\text { CDR1 }}{\text { AGCAACTACATGAGC }} \frac{\text { FRW2 }}{\text { TGGGTCCGCCAGGCTCCAGGGAAGGGGC }}$

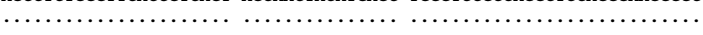
TGGAGTGGGTCTCA $\frac{\text { CDR2 }}{\text { GTTATTTATAGCGGTGGTAGCACATACTACGCAGACTCCGTGAAGGGC }}$

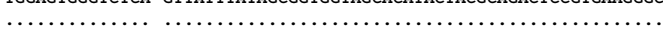
FRW3 CGATTCACCATCTCCAGACACAATTCCAAGAACACGCTGTATCTTCAAATGAACAGCCTGAGAGCT

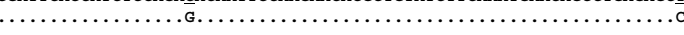
GAGGACACGGCCGTGTATTACTGTGCGAGAGA $\frac{\text { CDR3 }}{\text { TTGGGTTCGGGGAGTTATTATATGGGCTACTA }}$

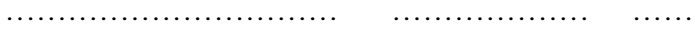

СTACTACGGTATGGACGTC $\frac{\text { FRW4 }}{\text { TGGGCCAAGGGACCACGGTCACCGTCTCCTCAG }}$

.........................................

b

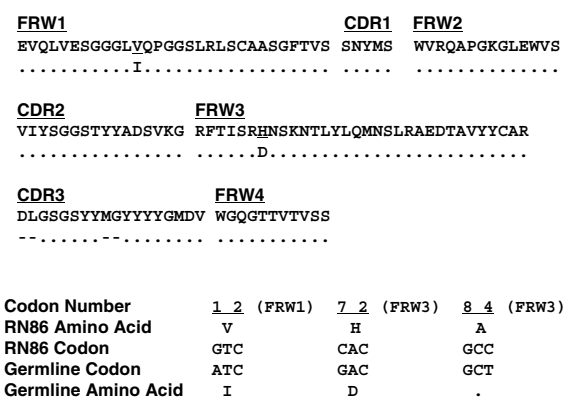

d $\frac{95}{96}$ $\begin{array}{cc}\frac{9}{D} & \frac{9}{L} \\ \text { GAT } & \text { TTG }\end{array}$ $979899 \frac{900}{100 a 100 b}$ $G \begin{array}{ccccccc}S & G & S & Y & Y & M\end{array}$

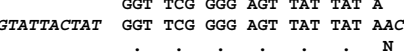

\begin{tabular}{cc}
\multirow{2}{*}{ G } & \multicolumn{2}{c}{$100 \mathrm{e} 100 \mathrm{f}$} \\
ATTA Y Y \\
C TAC TAC \\
C TAC TAC \\
\end{tabular}

Figure 7 RN86 heavy-chain (a) nucleotide sequence and (b) derived aminoacid sequence. The 53 germline gene (belonging to the $\mathrm{VH} 3$ family) was used along with the D3-10 and $\mathrm{JH} 6$ segments. Identical bases in the germline are indicated as dots and substitutions in the RN86 sequences are underlined. In (b), spaces $(-)$ in the germline sequence indicate positions of junctionally modified amino acids corresponding to the RN86 sequence. (c) The codon numbers, encoded amino acids and codons corresponding to the three mutations (two replacement, one silent as depicted by the dot) in RN86 are indicated, in comparison with the germline sequences. (d) Depiction of the V-D-J junction. RN86-encoded nucleotides and amino acids are shown, alongside the germline sequences. Dots correspond to conserved amino acids. A number of bases appeared to have been deleted from both the $V-D$ and $D-J$ junctions (shown in italics, detailed in the text), with some bases being added as well (shown underlined, detailed in the text). EMBL accession number: AJ548507

autoantibodies of distinct specificity; in the context of the disease, such responses could contribute to epitope spreading, and therefore to disease progression and pathology. As an initial assessment of the anti-RN86 specificity of purified anti-idiotypic antibodies, their capacity to prevent the interaction of RN86 to cellular target molecule(s) was analyzed; the binding of RN86 to MOLT-4 cells was reduced to background levels in their presence (data not shown). Such inhibition could be the result of either binding of the anti-idiotypic antibodies to RN86, thereby directly preventing its reactivity towards cellular antigen(s), or the binding of the anti-idioytpic antibodies to cellular targets, thereby inhibiting RN86 cellular reactivity via competition. Both effects probably contributed; while direct interaction of anti-idiotypic antibodies and RN86 was demonstrable via ELISA assays (data not shown), selfreactivity of anti-idiotypic antibodies was also apparent upon immunofluorescence analysis on the human glial cell line 

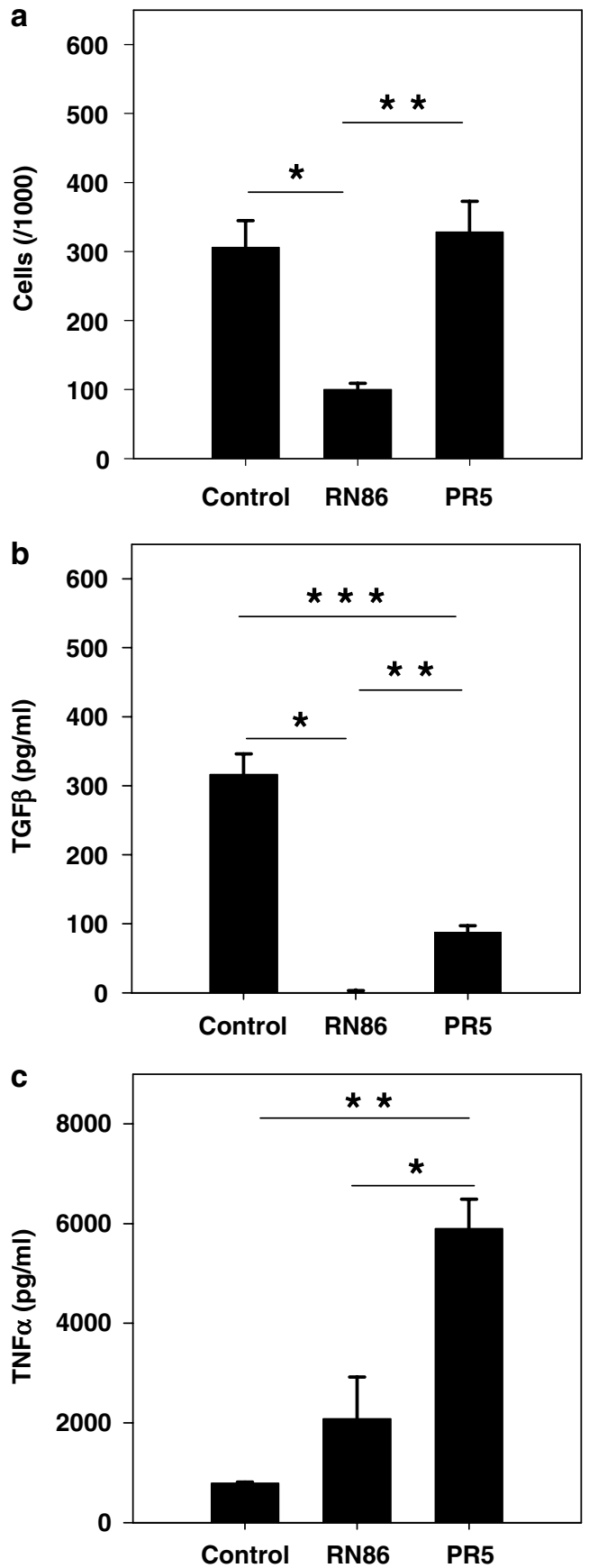

Figure 8 Influence of RN86 and PR5 on phagocytosis of apoptotic cells. (a) RN86 significantly reduced $\left({ }^{*} P=0.003\right)$ the phagocytosis of apoptotic cells over controls, and over PR5 containing cultures $\left({ }^{\star \star} P=0.003\right)$; the latter had no inhibitory influence upon phagocytosis. (b) Influence on TGF- $\beta$ secretion. Both antibodies suppressed secretion over controls, with RN86 being more active $\left({ }^{\star} P=0.0002\right)$ than PR5 $\left({ }^{* * *} P=0.0009\right)$ in this regard. A significant difference ${ }^{\star *} P=0.0004$ ) was observed between the two antibodies as well. (c) Influence upon TNF- $\alpha$ secretion. PR5 enhanced the secretion of the cytokine over controls $\left({ }^{\star *} P=0.0004\right)$ as well as over RN86-containing cultures $\left({ }^{*} P=0.01\right)$. Arithmetic means and standard errors are shown

PU-87; on permeabilized cells, significant cytoplasmic staining was observed, accompanied by intense, focal regions of reactivity (Figure 9a, left panel; the right panel indicates the relevant negative control). Similar results were obtained upon the human T-cell lines MOLT-4 and Jurkat (data not shown).

The specificity of the anti-self response of the anti-RN86 anti-idiotypic antibodies was analyzed. Since anti-La reactivity was predicted (based upon its known association with Ro60 in situ), the reactivity of these antibodies was assessed on camptothecin-treated Jurkat cells. Results are shown in Figure 9b. Firstly, it was observed that anti-idiotypic antibodies were reactive towards healthy cells, as observed by the rightward migration of the annexin-V-negative population (Figure 9b, top panel). This reactivity was independently confirmed on several cell lines (data not shown) and was in stark contrast to that observed for RN86 (the immunizing antibody) on nonpermeabilized cells (Figure 1a, top left panel), where most cells were nonreactive, and all reactive cells were apoptotic (Figure 1b). Secondly, a significant dualstained population was observed, indicating that the antibodies demonstrated enhanced binding towards apoptotic cells (Figure 9b, top panel). The relevant negative control (antibodies purified in analogous fashion from adjuvant-alone immunized rats) is depicted in the bottom panel of Figure 9b. In order to discern whether such reactivity was grossly different from that observed for the immunizing antibody RN86 (which demonstrated apoptotic cell specificity as well), Western blots were carried out on MOLT-4 lysates. Results are depicted in Figure 9c; X-ray films were deliberately overexposed to permit detection of proteins with minor reactivity towards respective antibodies. Lane 2 depicts the binding achieved when RN86 was employed; as expected, the characteristic recognition of proteins between 50 and $75 \mathrm{kDa}$ was observed. Lane 3 shows the recognition profile of purified anti-idiotypic antibodies. It was apparent that dominant reactive proteins exhibited molecular weights between 30 and $50 \mathrm{kDa}$, with evidence of discrete (but minor) reactivity at $\approx 60 \mathrm{kDa}$. Lanes 1 and 4 depict negative controls, with lysatecontaining nitrocellulose strips incubated with goat antihuman IgM-HRPO and goat anti-rat IgG-HPRO, respectively.

Lastly, the reactivity of purified anti-RN86 anti-idiotypic antibodies was assessed against a panel of common autoantigens. Many autoantigens were recognized (Figure 9d; checked gray bars). For comparison, the specificity of the immunizing antibody (RN86) is depicted in the same graph as well. (Figure 9d, black bars). It was apparent that the two reactivities were disparate, with the anti-idiotypic sera displaying a wider spectrum; while RN86 preferentially recognized Ro52 and Ro60 (as previously discussed), anti-RN86 antiidiotypic antibodies revealed recognition of the $A(34 \mathrm{kDa})$, SmD (16 kDa), Ro60 (60 kDa), Ro52 (52 kDa) and La (48 kDa) proteins (Figure $7 d$ ). These results correlated with Western blot data as far as four of the five specificities were concerned. Thus, Western blot, FACS and ELISA data all indicated that anti-RN86 anti-idiotypic antibodies were additionally directed against self-antigens not recognized by RN86.

\section{Discussion}

Cell death in multi-cellular organisms can follow two broad pathways, each with distinct physiological consequences. Necrotic cell death, which follows injury and is often 
a

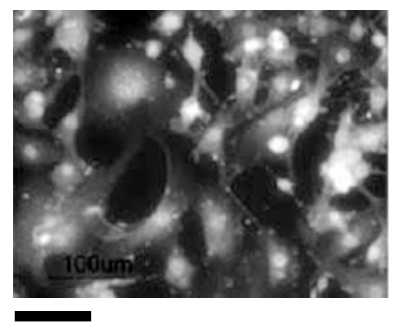

b

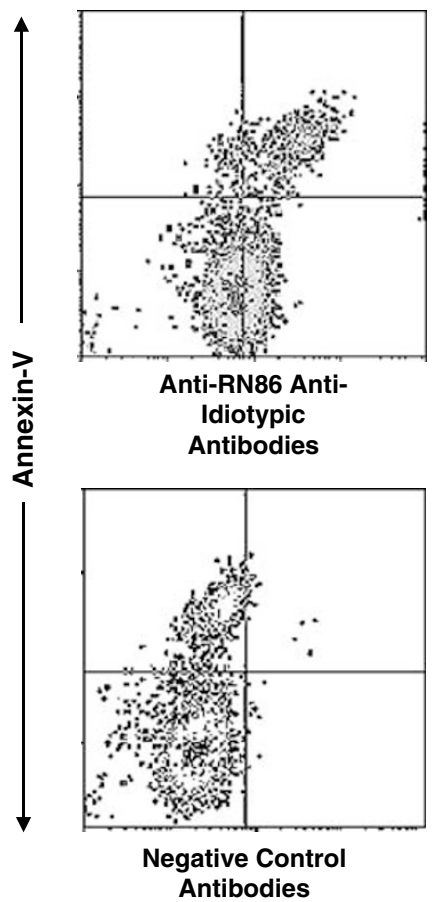

C
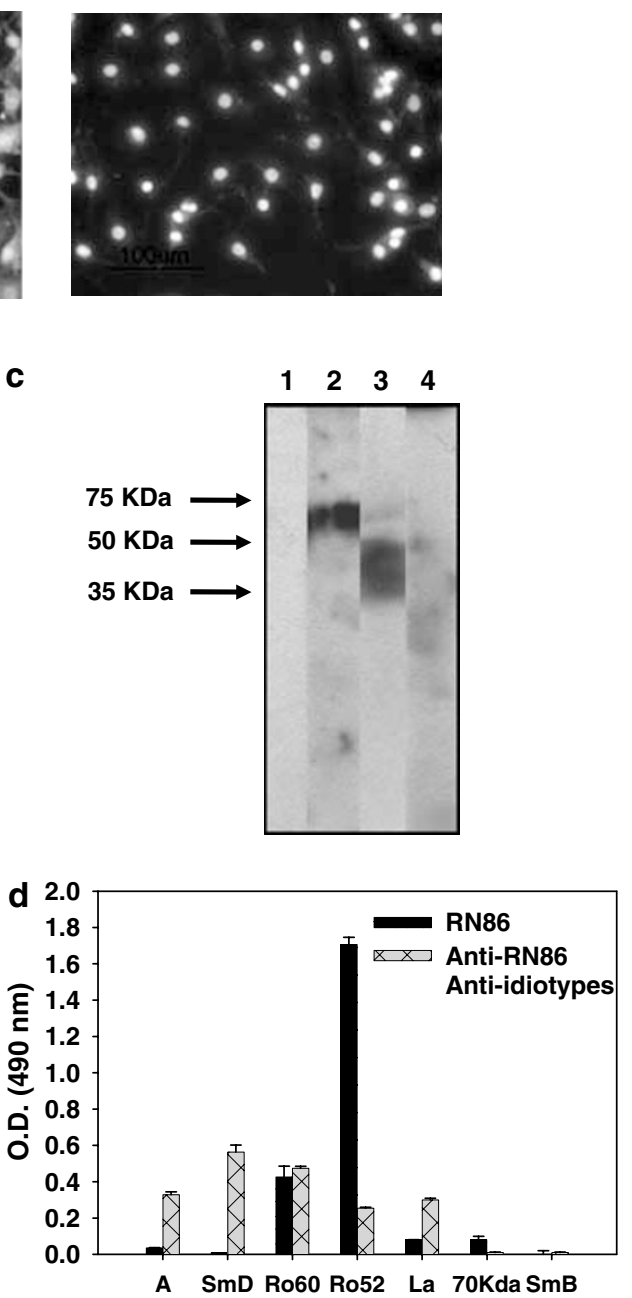

Figure 9 Characterization of anti-RN86 anti-idiotypic antibodies. (a) Immunofluorescence analysis on permeabilized glial cells (PU-87). Left panel: Intense cytoplasmic localization along with a punctated staining pattern was observed. Right panel: Negative control, showing lack of cytoplasmic binding of antibodies elicited by adjuvant alone. In both cases, nuclei were counterstained with PI. Bar, $100 \mu \mathrm{m}$. (b) Top panel: Reactivity of anti-RN86 anti-idiotypic antibodies to healthy cells (as demonstrated by the rightward shift of annexin-V unstained cells) and enhanced recognition of apoptotic (annexin-V positive) cells. Bottom panel: Negative control (antibodies elicit by adjuvant alone), demonstrating lack of such binding. (c) Western blot of RN86 (lane 2) and purified anti-RN86 anti-idiotypic antibodies (lane 3) on MOLT-4 lysate. Lane 1, anti-human HRPO control; Lane 4, anti-rat HRPO control. (d) ELISA of anti-RN86 anti-idiotypic antibodies on recombinant human autoantigens (checked gray bars). Reactivity of the immunizing antibody (RN86) is shown for reference (black bars). Arithmetic means and standard errors are shown

accompanied by inflammatory processes, involves cellular swelling and loss of membrane integrity. Apoptotic (or programmed) cell death, on the other hand, is considered quiescent and noninflammatory, and is generally thought of as more physiological than pathological. ${ }^{22}$ Apoptosis is involved in both tissue differentiation and organ homeostasis and is of particular relevance to the immune system, as exemplified by thymocyte death during negative selection, as well as by death induced in virally infected cells by the action of granzymes released by $\mathrm{CD} 8^{+} \mathrm{T}$ lymphocytes.

Since apoptotic death is so central to organismal well being, mechanisms that mediate recognition and phagocytosis of apoptotic debris have co-evolved. It is becoming increasingly clear that systemic autoimmune pathology can result due to aberrations in either the quantum of cell death or in the efficiency of disposal of cellular corpses. An increased rate of apoptosis was observed in PBMCs isolated from lupus patients. ${ }^{5}$ Cells undergoing apoptosis manifest a number of morphological and biochemical changes, including membrane blebbing, modification in plasma membrane configuration, cytoplasmic contraction and packaging of cytoplasmic proteins into membrane-bound vesicles. ${ }^{22}$ Apoptotic cell specific molecular patterns (ACAMPs), comprising prominent autoantigens (such as DNA, histones and the ribonucleoprotiens Ro and La), appear upon membrane blebs in advance of cellular lysis and are readily accessible by specific autoreactive antibodies. ${ }^{23}$ These appear to segregate into two different populations on the cell surface. Large apoptotic bodies arise from condensed fragmented nuclei and contain nucleosomes, Ro and La and snRNPs, whereas small blebs contain fragmented endoplasmic reticulum (ER) and ribosomal antigens, along with Ro. ${ }^{6}$ Systemic exposure of normal as well as lupus-prone mice to apoptotic cells induces secretion of autoantibodies, confirming their auto-antigenicity. ${ }^{7}$ 
Investigation into the mechanisms and molecules involved in the phagocytic recognition of death-specific surface structures present on apoptotic cells is an ongoing area of research. Many molecules on the phagocyte have been implicated; ${ }^{24}$ the recognition of PS on apoptotic cells, with or without the conjunction of intermediary molecules, appears to be important. ${ }^{20,25,26}$ The notion that defects in the clearance of apoptotic debris can give rise to a lupus-like pathology has been supported by a number of knockout mouse models; ${\mathrm{C} 1 \mathrm{q}^{-1-}, 27} \mathrm{c}-\mathrm{mer}^{-1-9}$ and most recently MFG-E8 $8^{-1-28}$ mice. Injection of mutant MFG-E8 (engineered to mask PS and reduce apoptotic cell uptake) also elicits autoimmune responses, particularly when administered along with apoptotic cells. $^{29}$

Since apoptotic cells are considered the original antigenic insult, the consequences of the early autoimmune response to surface components on such cells assume obvious importance. It is probable that both the nature of the antigens recognized as well as the nature of the elicited antibodies and their downstream biological effects could influence the future course of disease. The human monoclonal antibody RN86 was reactive towards cytoplasmic antigens, which appeared to be translocated to the surface in the late stages of apoptosis. The kinetic parallels between antibody binding and $\mathrm{PI}$ recognition, as well as their colocalization on the apoptotic cell surface, is expected, since degraded nucleosomal material is also similarly targeted. ${ }^{23}$ The ubiquitous nature of the antigens recognized by the antibody is consistent with the conserved nature of the apoptotic process, and the commonality of biochemical pathways of death that are known to occur, irrespective of cell lineage. Ro52 and Ro60, the molecules recognized by RN86, are RNPs of unknown function in higher organisms. No sequence homology exists between these two molecules, and interaction between them has not been convincingly demonstrated. AntiRo antibodies are present in $30-50 \%$ of lupus patients, and, when present in pregnant women (in association with anti-La responses), are associated with congenital heart block in offspring. ${ }^{30}$

In many instances, somatic mutation may play an important role in the development of pathogenic, highaffinity autoantibody responses ${ }^{3,31}$ and some mutated, high-affinity anti-self antibodies demonstrate lower affinity for antigen when 'revertant' mutations are introduced. The inhibitory influence of RN86 upon phagocytic uptake of apoptotic cells is particularly relevant, given the fact that the antibody does not appear to carry significantly mutated V regions, although the junctional changes that the antibody exhibits would no doubt influence antigenic recognition. The data would argue in favor of an influence upon apoptosis of ACAMPs (such as Ro52 and Ro60) that appear on the cell surface late in the apopotic cascade. It is unknown at this time whether the inhibitory phagocytic influence of RN86 is due to either direct effects or steric hindrance. The specificity of inhibition and the strict dependence of the observed inhibitory effects on the appearance of neoepitopes upon apoptosis were revealed when PR5 (a human monoclonal antibody that does not discriminate between healthy and apoptotic cells) was employed as a heavy- and light-chain isotype control.
If ACAMPs like Ro60 and Ro52 indeed mediate the phagocytic uptake of apoptotic cells, receptors for these molecules may exist on the phagocyte surface; efforts are currently ongoing to identify and characterize such interactions. In this connection, a recent report describing a lupuslike phenotype in mice lacking $\mathrm{Ro}^{32}$ is of interest. Though the reasons for the onset of autoimmunity remain speculative, the authors suggest a protective role for Ro60, based upon its reported interaction with defective rRNA in Xenopus laevis oocytes. An alternative explanation, that Ro like molecules may be involved in the phagocytic uptake of apoptotic cells, is given credence by our results.

As discussed above, heightened apoptosis as well as impaired clearance have been implicated in the lupus. Antibodies of the specificity of RN86 appear to bridge these two phenomena; increased apoptosis in susceptible individuals would lead to the generation of antibodies like RN86, the presence of which would lead to impaired uptake. It is clear that this could lead to increased availability of cellular debris, and so could constitute a self-perpetuating cycle. Previous reports suggest that distinct phagocytic outcomes can result, depending on the nature of the targeted ACAMP. Murine antibodies directed against low-density lipoproteins on apoptotic cells can inhibit phagocytosis. ${ }^{33}$ Immunization of mice with apoptotic cells resulted in an IgM monoclonal antibody against an ACAMP that, like RN86, was detected on only upon cells at the late stages of apoptosis. Though the antigen remained uncharacterized, the antibody was shown to inhibit apoptotic cell internalization. ${ }^{34}$ In contrast to these inhibitory effects on uptake, polyclonal anti-phospholipid antibodies increased the uptake of apoptotic cells. ${ }^{16}$ 'Natural' IgM has also been shown to have an enhanced ability to bind to apoptotic cells, and to promote phagocytosis. ${ }^{12}$ These observations differed from ours (as well as those of others ${ }^{33,34}$ ); normal human IgM was included as a control in all our experiments, but was never found to bind to an extent equivalent to RN86. The fact that our experiments were conducted at much lower concentrations of antibody as well as the differing protocols employed for the induction of apoptosis may account for the discrepancy.

Internalization of apoptotic cells by phagocytes normally inhibits the release of proinflammatory cytokines such as TNF- $\alpha$, promotes the secretion of cytokines such as TGF- $\beta$, and is therefore considered an anti-inflammatory event. ${ }^{21}$ Apoptotic cells induce immunosuppressive cytokine responses even in the presence of a proinflammatory signal such as LPS. ${ }^{35}$ However, the presence of human polyclonal anti-phospholipid antibodies during phagocytosis can enhance the secretion of TNF- $\alpha$ by macrophages ${ }^{16}$ and the binding of polyclonal human anti-Ro and anti-La antibodies to apoptotic fetal cardiocytes results in enhanced TNF- $\alpha$ secretion by cocultured macrophages. ${ }^{36}$ When PR5 was employed as the opsonizing antibody, TNF- $\alpha$ secretion was significantly increased, even though no difference was observed in the number of phagocytosed cells over the control. It thus appeared that the quantum of TNF- $\alpha$ secretion was dependent not simply on the number of phagocytosed apoptotic cells, but rather on the number of opsonized phagocytosed apoptotic cells. Interestingly, despite the fact that apoptotic cells opsonized by RN86 were less efficiently phagocytosed, 
the antibody caused a significant decrease in the secretion of TGF- $\beta$. It can be speculated that signaling for TGF- $\beta$ is somehow influenced by the relative stability of the two immune complexes; data generated in our laboratory suggest that RN86, as well as several other apoptotic-cell specific mouse monoclonal antibodies, form more stable immune complexes than PR5 at physiological temperatures (data not shown). It is clear that the overall effect of antibodies of specificities like RN86 and PR5 would serve to increase inflammation and decrease the down-modulatory effect of suppressor cytokines. When phagocytosis is additionally impaired (as with RN86), these influences may lead to an amplification of the autoimmune response.

Anti-idiotypic antibodies have been shown to mimic the inciting antigen in conformation, antigenicity and, in some instances, in biological function. ${ }^{37}$ Purified anti-RN86 antiidiotypic antibodies revealed more extensive reactivity than theoretically anticipated; many additional molecules that exist upon the cell surface of healthy as well as apoptotic cells, and in the cytoplasm, were targeted. Unexpected diversification of the immune response to cardiolipin and Ro has also been reported upon immunization of anti-dsDNA antibodies bearing the $16 / 6$ idiotype. ${ }^{38}$ The reasons for these results are not clear, but it can be postulated that unappreciated levels of idiotypic inter-connectivity exist among autoimmune responses. Thus, along with the well-recognized phenomenon of conventional antigen diversification, where autoimmune responses to an epitope on one molecule diversify to include other associated molecules, ${ }^{39,40}$ the idiotypic network may also serve to broaden the spectrum of targeted ribonucleoprotein autoantigens.

Antibodies that target ACAMPs are expected to arise both at the initial onset of disease, as well as during the periodic flares that characterize systemic autoimmunity. Such immunoglobulins can either be essentially germline encoded (although they demonstrate distinct characteristics from 'natural' IgM) or can be somatically mutated. Our results demonstrate that such antibodies could contribute towards pathogenesis by three distinct mechanisms: by reducing the number of apoptotic cells phagocytosed, thereby increasing the peripheral availability of autoantigenic material, by reducing the secretion of TGF- $\beta$, thereby helping to elicit a more proinflammatory environment, and by stimulating epitope spreading via the idiotypic network, thereby increasing the range of molecular targets.

\section{Materials and Methods}

\section{Lymphoblastoid cell lines}

This study was approved by relevant Institutional Ethics Committees. Peripheral blood mononuclear cells were isolated from the blood of two patients (RN and PR) (who satisfied the 1997 updated criteria of the American College of Rheumatology for SLE) by differential centrifugation over Ficoll-Hypaque (Pharmacia, Sweden). Isolated cells were washed three times with $50 \mathrm{mM}$ PBS, $\mathrm{pH} 7.4$, resuspended to a concentration of $6 \times 10^{6} \mathrm{cells} / \mathrm{ml}$ in RPMl 1640 containing $2 \mathrm{mM}$ L-glutamine, $100 \mathrm{U} / \mathrm{ml}$ penicillin G sodium, $100 \mu \mathrm{g} / \mathrm{ml}$ streptomycin sulfate, $2.36 \mathrm{mg} / \mathrm{ml}$ HEPES and supplemented with $10 \%$ fetal calf serum (hereafter referred to as CRPMIH). PBMC were plated in 96-well tissue culture plates at 1000 cells per well. $10^{5}$ freshly irradiated (3000 rads) allogeneic PBMC were then added to each well as 'feeders'. Finally, culture supernatant of the cell line B95-8 was added as a source of Epstein-Barr virus. Individual lymphoblastoid cell lines were transferred to 24-well plates and then to $25 \mathrm{~cm}^{2}$ flasks. Cells were then cryo-preserved by standard procedures and stored at $-135^{\circ} \mathrm{C}$.

The human T-cell line MOLT-4 was grown in CRPMIH. Viable cells were isolated by Ficoll-Hypaque centrifugation and subcultured at $5 \times 10^{4}$ cells/ $\mathrm{ml}$. Apoptosis was induced $24 \mathrm{~h}$ later by incubation in the presence of $2.5 \mu \mathrm{M}$ camptothecin (Sigma Chemical Company, USA). $5 \times 10^{5}$ control, drug-treated or permeabilized cells (achieved by brief incubation in chilled methanol containing $0.001 \%$ Triton $X-100$ ) were suspended in FACS buffer (PBS containing 1\% BSA and $0.2 \%$ sodium azide) and incubated with the lymphoblastoid supernatants for $30 \mathrm{~min}$ at $4^{\circ} \mathrm{C}$. After three washes in FACS buffer, appropriately diluted goat anti-human Ig-FITC (Jackson ImmunoResearch, USA) was added and a further incubation for 30 min was carried out. Cells were then washed twice with FACS buffer. Apoptotic cells were washed a third time in FACS buffer containing $2.5 \mathrm{mM}$ $\mathrm{CaCl}_{2}$. Annexin V-PE ( $5 \mu \mathrm{l}$ Pharmingen, USA) diluted in $100 \mu \mathrm{l}$ of the same buffer was then added and incubation was carried out at room temperature for $15 \mathrm{~min}$; in some cases, parallel cultures were incubated with propidium iodide (PI; Pharmingen, USA). Cells were then processed for fluorescence microscopy or analysis on a Becton Dickinson FACS machine. Additionally, trypan blue reactivity was scored.

\section{Human monoclonal antibodies}

Cells secreting antibodies that specifically recognized apoptosing cells, or recognizing healthy, nonapoptotic cells as identified above were fused with the heteromyleoma $\mathrm{K}_{6} \mathrm{H}_{6} / \mathrm{B}_{5}$ using polyethylene glycol. ${ }^{14}$ Cells were resuspended in medium containing hypoxanthine $(0.1 \mathrm{mM})$ and thymidine $(0.016 \mathrm{mM})$, and plated at 3000-5000 per well. Selection medium containing aminopterin $(0.0004 \mathrm{mM})$ and ouabain $(0.001 \mathrm{mM})$ was added 1 day after fusion. Supernatants of growing cultures were screened for reactivity using FACS as described above, and cells secreting relevant antibodies were cloned at least three times by limiting dilution to ensure monoclonality. Two antibodies were generated; RN86 (IgM $[\kappa]$ ), an antibody that specifically targeted late-stage apoptotic cells, and PR5 (IgM $[\kappa])$, an antibody that did not distinguish between healthy and apoptotic cells.

\section{Western blots}

Lysates from a variety of different cell lines were employed. $10^{6}$ cells were incubated in $500 \mu$ l lysis buffer (PBS containing 0.5\% NP-40 and a proteolytic inhibitor cocktail (Calbiochem, USA)) for $1 \mathrm{~h}$ at $4^{\circ} \mathrm{C}$. The suspension was then centrifuged at $15000 \times g$ to precipitate the nonsoluble fraction and lysates were normalized for protein content. Reducing SDS-PAGE and Western blots were carried out by standard procedures. Enhanced chemiluminiscence (ECIL; Amersham, UK) was employed to visualize reactive moieties on X-ray film.

\section{ELISA}

Recombinant autoantigens were a kind gift of Dr. Shu Man Fu, University of Virginia, Charlottesville, VA, USA. Direct binding ELISAs were carried out to determine the autoantigenic specificity of the antibodies. Recombinant human ribonucleoproteins (U1-RNP A, SmB, SmD, Ro60, Ro52, La, U1-RNP $70 \mathrm{kDa}$ ) were absorbed onto Immulon-2 (Dynatech Inc., USA) ELISA plates in $50 \mathrm{mM}$ sodium carbonate-bicarbonate buffer, 
$\mathrm{pH} 9.6$, by incubation for $18 \mathrm{~h}$ at $4^{\circ} \mathrm{C}$. All subsequent incubations were for $2 \mathrm{~h}$ at room temperature. After two washes with $50 \mathrm{mM}$ PBS, $\mathrm{pH} 7.4$, containing $0.05 \%$ Tween-20 (PBST), residual binding sites were saturated by incubation with PBS containing $2 \%$ bovine serum albumin (BSA). Plates were washed with PBST and culture supernatants (diluted in PBS containing $0.1 \%$ Tween-20 and $3 \%$ BSA) were added. After further incubation and extensive washing, an appropriately diluted goat antihuman secondary reagent (Jackson ImmunoResearch, USA) was added and another incubation carried out. The enzymatic reaction was developed with an orthophenylene diamine-containing substrate and optical densities at $490 \mathrm{~nm}$ determined on an ELISA reader.

Assays were carried out to ascertain whether the epitopes recognized by the apoptotic cell-specific human monoclonal antibody RN86 upon Ro60 and Ro52 (see results) were also commonly targeted in the human polyclonal autoimmune response. Nine sera from SLE patients were analyzed for R052 and R060 reactivity by direct binding ELISA assays, with nine normal human sera serving as negative controls. Subsequently, the capacity of these sera to inhibit the binding of purified, biotinylated RN86 to Ro52 and Ro60 was individually analyzed in a competitive ELISA format.

\section{Polymerase chain reaction}

RNA was extracted from subcloned hybridoma cells using Trizol. Total RNA $(3 \mu \mathrm{g})$ was reversed transcribed with an oligo dT primer and SuperScript II reverse transcriptase (Gibco-BRL, USA). Anchored PCR for amplification of $\mathrm{V}_{\mathrm{H}}$ and $\mathrm{V}_{\mathrm{K}}$ was carried out. ${ }^{15}$ Oligonucleotide primers for the amplification of $V_{\kappa}$ were PAN $\left(5^{\prime}\right.$-CACGTCGACAGGCGGCCGCGG TAC), PANpoly C (5'-CACGTCGACAGGCGGCCGCGGTACCCCCCCC CCCCCC) and HKC (5'-CCGAAGCTTGAAGATGAAGACAGATGGTGC). The three primers for the amplification of $V_{H}$ were SAN $\left(5^{\prime}\right.$ CTACGAGCTCAGGCGGCCGCGGAC), SAN poly $C$ (5'-CTACGAGCT CAGGCGGCCGCGGACCCCCCCCCCCCCC) and CMC (5'-GAGAAG CTTTGGGGCGGATGCACTCC).

PCR products were cloned into the pGEM ${ }^{\mathbb{R}}$-T Easy vector (Promega, USA) at the EcoRI site and sequenced on an automatic sequencer (Perkin-Elmer, USA). Sequence analysis was conducted using on-line NCBI (http://www.ncbi.nlm.nih.gov/igblast/), V BASE (http://www.mrc-cpe. cam.ac.uk/ALIGNMENTS.php?menu = 901) and IGMT (http://imgt.cines. fr/cgi-bin/IMGTdnap.jv?livret =0\&Option = humanlg) databases.

\section{Phagocytosis, cytokine analysis}

The relative influence of the two antibodies on the phagocytosis of apoptotic cells was determined. Assays were carried out as previously described by other investigators, ${ }^{16}$ with certain modifications. Briefly, THP-1 (human monocytic) cells were activated for $72 \mathrm{~h}$ in the presence of $160 \mathrm{nM}$ phorbol-12-myristate-13-acetate (PMA) to promote adherence and enhance phagocytic capacity. Jurkat (Human T) cells were pulsed with ${ }^{3} \mathrm{H}$-thymidine for $28-30 \mathrm{~h}\left(0.5 \mu \mathrm{Ci}\right.$ per $\left.0.5 \times 10^{6} \mathrm{cells}\right)$. Apoptosis was induced as before, or essentially as described, ${ }^{17}$ with certain modifications; cells were irradiated by UV $\left(1 \mathrm{~J} / \mathrm{cm}^{2}, 15 \mathrm{~min}\right)$ and subsequently cultured overnight in serum-free medium. Apoptotic cells $(12 \mathrm{~h}$ postinduction) were incubated with $10 \mu \mathrm{g}$ of purified PR5 or RN86 (obtained as described below) for $1 \mathrm{~h}$ at $37^{\circ} \mathrm{C}$, followed by another incubation for $1 \mathrm{~h}$ at $4^{\circ} \mathrm{C}$. 'Charged' cells were incubated with activated THP-1 cells for $1 \mathrm{~h}$ at $4^{\circ} \mathrm{C}$ and then $2 \mathrm{~h}$ at $37^{\circ} \mathrm{C}$. Supernatants were stored for subsequent analysis of tumor necrosis factor- $\alpha$ (TNF- $\alpha)$ and transforming growth factor- $\beta$ (TGF- $\beta$ ) levels by BD OPT ${ }^{\mathrm{TM}}$ (Becton Dickinson, USA) ELISA kits, using protocols supplied by the manufacturer. Wells were gently washed to remove nonphagocytosed and surface-attached apoptotic cells. THP-1 cells were then lysed by brief incubation in PBS containing 1\% NP40, and cell-associated radioactivity assessed in a $\beta$-counter (Beckman, USA).

\section{Anti-idiotypic reactivity}

Human monoclonal antibodies were isolated from culture supernatant by the gradual addition of solid ammonium sulfate, to a final concentration of $40 \% \mathrm{w} / \mathrm{v}$. Immunoglobulin fractions were precipitated by centrifugation at $14000 \times g$ at $4^{\circ} \mathrm{C}$ for $20 \mathrm{~min}$. The resulting pellet was resuspended in $0.1 \mathrm{M}$ Tris, $\mathrm{pH} 8.0$ (supplemented with $1 \mathrm{M} \mathrm{NaCl}$ ) and extensively dialyzed against acidified water ( $\mathrm{pH}$ 5.0-6.0). Precipitated IgM was isolated by centrifugation at $14000 \times g$ at $4^{\circ} \mathrm{C}$ for $20 \mathrm{~min}$ and resuspended in $10 \mathrm{mM}$ PBS, pH 7.4. ${ }^{18}$ Antibodies were additionally purified on Hi-Trap affinity columns (Amersham, UK). Normal IgM was purified from pooled normal human sera obtained from healthy volunteers in an analogous fashion. Purified RN86 and normal human IgM were coupled to CNBr-activated Sepharose (Pharmacia, Sweden) as per the manufacturer's instructions.

Female Wistar rats, 8-week-old, were administered three subcutaneous injections of purified RN86 antibodies at fortnightly intervals; the antigen solution was appropriately diluted (50 $\mu \mathrm{g}$ per injection) in PBS and emulsified in an equal volume of Complete (for primary injections) or Incomplete (for subsequent injections) Freund's adjuvant. Control rats were immunized with adjuvant alone. Sera from immunized animals were pooled, appropriately diluted in PBS and loaded onto the RN86-coupled affinity column; after extensive washes with PBS to remove unbound antibodies, RN86-reactive antibodies were eluted with $0.1 \mathrm{M}$ glycine $\mathrm{HCl}$, $\mathrm{pH}$ 2.5. The $\mathrm{pH}$ of the eluates was immediately neutralized with $1.5 \mathrm{M}$ Tris, $\mathrm{pH}$ 8.8. Protein-containing fractions of the eluate were pooled and loaded onto the IgM-coupled column and the flow-through collected. Sera from both experimental and control groups of animals were similarly treated. Purified anti-idiotypic antibodies were assessed for reactivity by Western blotting, ELISA and FACS analysis as described previously, with appropriate modifications in secondary reagents.

\section{Acknowledgements}

This study was supported by core and extramural grants from the Department of Biotechnology, Government of India.

\section{References}

1. von Muhlen CA and Tan EM (1995) Autoantibodies in the diagnosis of systemic rheumatic diseases. Semin. Arthritis. Rheum. 24: 323-358

2. Koike T and Matsuura E (1999) Immunology of anti-phospholipid antibodies. In Systemic Lupus Erythematosus, Lahita R (ed) San Diego: Academic Press pp. 813-827

3. Diamond B, Katz JB, Paul E, Aranow C, Lustgarten D and Scharff MD (1992) The role of somatic mutation in the pathogenic anti-DNA response. Annu. Rev. Immunol. 10: 731-757

4. Salomonsson S, Dorner T, Theander E, Bremme K, Larsson $P$ and WahrenHerlenius M (2002) A serologic marker for fetal risk of congenital heart block. Arthritis Rheum. 46: 1233-1241

5. Emlen W, Niebur J and Kadera R (1994) Accelerated in vitro apoptosis of lymphocytes from patients with systemic lupus erythematosus. J. Immunol. 152: 3685-3692

6. Casciola-Rosen LA, Anhalt G and Rosen A (1994) Autoantigens targeted in systemic lupus erythematosus are clustered in two populations of surface structures on apoptotic keratinocytes. J. Exp. Med. 179: 1317-1330

7. Mevorach D, Zhou JL, Song X and Elkon KB (1998) Systemic exposure to irradiated apoptotic cells induces autoantibody production. J. Exp. Med. 188: 387-392 
8. Napirei M, Karsunky H, Zevnik B, Stephan $H$, Mannherz HG and Moroy $T$ (2000) Features of systemic lupus erythematosus in Dnase1-deficient mice. Nat. Genet. 25: 177-181

9. Cohen PL, Caricchio R, Abraham V, Camenisch TD, Jennette JC, Roubey RA, Earp HS, Matsushima G and Reap EA (2002) Delayed apoptotic cell clearance and lupus-like autoimmunity in mice lacking the c-mer membrane tyrosine kinase. J. Exp. Med. 196: 135-140

10. Botto M (1998) C1q knock-out mice for the study of complement deficiency in autoimmune disease. Exp. Clin. Immunogenet. 15: 231-234

11. Ehrenstein MR, Cook HT and Neuberger MS (2000) Deficiency in serum immunoglobulin $(\mathrm{Ig}) \mathrm{M}$ predisposes to development of $\mathrm{IgG}$ autoantibodies. J. Exp. Med. 191: 1253-1258

12. Kim SJ, Gershov D, Ma X, Brot N and Elkon KB (2002) I-PLA(2) activation during apoptosis promotes the exposure of membrane lysophosphatidylcholine leading to binding by natural immunoglobulin $M$ antibodies and complement activation. J. Exp. Med. 196: 655-665

13. Mendlovic S, Brocke S, Shoenfeld Y, Ben-Bassat M, Meshorer A, Bakimer R and Mozes $E$ (1988) Induction of a systemic lupus erythematosus-like disease in mice by a common human anti-DNA idiotype. Proc. Natl. Acad. Sci. USA 85: 2260-2264

14. Carroll WL, Thielemans K, Dilley J and Levy R (1986) Mouse $\times$ human heterohybridomas as fusion partners with human B cell tumors. J. Immunol. Methods 89: 61-72

15. Fang Q, Kannapell CC, Fu SM, Xu S and Gaskin F (1995) VH and VL gene usage by anti-beta-amyloid autoantibodies in Alzheimer's disease: detection of highly mutated $V$ regions in both heavy and light chains. Clin. Immunol. Immunopathol. 75: 159-167

16. Manfredi AA, Rovere P, Galati G, Heltai S, Bozzolo E, Soldini L, Davoust J, Balestrieri G, Tincani A and Sabbadini MG (1998) Apoptotic cell clearance in systemic lupus erythematosus. I. Opsonization by antiphospholipid antibodies. Arthritis Rheum. 41: 205-214

17. Taylor PR, Carugati A, Fadok VA, Cook HT, Andrews M, Carroll MC, Savill JS, Henson PM, Botto M and Walport MJ (2000) A hierarchical role for classical pathway complement proteins in the clearance of apoptotic cells in vivo. J. Exp. Med. 192: 359-366

18. Garcia-Gonzalez M, Bettinger S, Ott S, Olivier $P$, Kadouche $J$ and Pouletty $P$ (1988) Purification of murine IgG3 and IgM monoclonal antibodies by euglobulin precipitation. J. Immunol. Methods 111: 17-23

19. Kabat EA, Wu TT, Perry HM, Gottesman KS and Foeller C (1991) Sequences of Proteins of Immunological Interest (Washington, DC: US Department of Health and Human Services) p. 2180

20. Fadok VA, Bratton DL and Henson PM (2001) Phagocyte receptors for apoptotic cells: recognition, uptake, and consequences. J. Clin. Invest. 108: 957-962

21. Fadok VA, Bratton DL, Konowal A, Freed PW, Westcott JY and Henson PM (1998) Macrophages that have ingested apoptotic cells in vitro inhibit proinflammatory cytokine production through autocrine/paracrine mechanisms involving TGF-beta, PGE2, and PAF. J. Clin. Invest. 101: 890-898

22. Wyllie AH, Kerr JF and Currie AR (1980) Cell death: the significance of apoptosis. Int. Rev. Cytol. 68: 251-306

23. Cocca BA, Cline AM and Radic MZ (2002) Blebs and apoptotic bodies are B cell autoantigens. J. Immunol. 169: 159-166

24. Savill J, Dransfield I, Gregory C and Haslett C (2002) A blast from the past: clearance of apoptotic cells regulates immune responses. Nat. Rev. Immunol. 2: $965-975$
25. Balasubramanian K, Chandra J and Schroit AJ (1997) Immune clearance of phosphatidylserine-expressing cells by phagocytes. The role of beta2-glycoprotein I in macrophage recognition. J. Biol. Chem. 272: 31113-31117

26. Hanayama R, Tanaka M, Miwa K, Shinohara A, Iwamatsu A and Nagata S (2002) Identification of a factor that links apoptotic cells to phagocytes. Nature 417: $182-187$

27. Walport MJ, Davies KA and Botto M (1998) C1q and systemic lupus erythematosus. Immunobiology 199: 265-285

28. Hanayama R, Tanaka M, Miyasaka K, Aozasa K, Koike M, Uchiyama $Y$ and Nagata S (2004) Autoimmune disease and impaired uptake of apoptotic cells in MFG-E8-deficient mice. Science 304: 1147-1150

29. Asano K, Miwa M, Miwa K, Hanayama R, Nagase H, Nagata S and Tanaka M (2004) Masking of phosphatidylserine inhibits apoptotic cell engulfment and induces autoantibody production in mice. J. Exp. Med 200: 459-467

30. Reed BR, Lee LA, Harmon C, Wolfe R, Wiggins J, Peebles C and Weston WL (1983) Autoantibodies to SS-A/Ro in infants with congenital heart block. J. Pediatr. 103: 889-891

31. Demaison C, Ravirajan CT, Isenberg DA and Zouali M (1995) Analysis of variable region genes encoding anti-Sm and anti-cardiolipin antibodies from a systemic lupus erythematosus patient. Immunology 86: 487-494

32. Xue D, Shi H, Smith JD, Chen X, Noe DA, Cedervall T, Yang DD, Eynon E, Brash DE, Kashgarian M, Flavell RA and Wolin SL (2003) A lupus-like syndrome develops in mice lacking the Ro $60-\mathrm{kDa}$ protein, a major lupus autoantigen. Proc. Natl. Acad. Sci. USA 100: 7503-7508

33. Chang MK, Bergmark C, Laurila A, Horkko S, Han KH, Friedman P, Dennis EA and Witztum JL (1999) Monoclonal antibodies against oxidized low-density lipoprotein bind to apoptotic cells and inhibit their phagocytosis by elicited macrophages: evidence that oxidation-specific epitopes mediate macrophage recognition. Proc. Natl. Acad. Sci. USA 96: 6353-6358

34. Fujii C, Shiratsuchi A, Manaka J, Yonehara S and Nakanishi Y (2001) Difference in the way of macrophage recognition of target cells depending on their apoptotic states. Cell Death Differ. 8: 1113-1122

35. Byrne A and Reen DJ (2002) Lipopolysaccharide induces rapid production of IL-10 by monocytes in the presence of apoptotic neutrophils. J. Immunol. 168: 1968-1977

36. Miranda-Carus ME, Askanase AD, Clancy RM, Di Donato F, Chou TM, Libera MR, Chan EK and Buyon JP (2000) Anti-SSA/Ro and antiSSB/La autoantibodies bind the surface of apoptotic fetal cardiocytes and promote secretion of TNF-alpha by macrophages. J. Immunol. 165: 5345-5351

37. Eng $\mathrm{H}$ and Lefvert AK (1988) Isolation of an antidiotypic antibody with acetylcholine-receptor-like binding properties from myasthenia gravis patients. Ann. Inst. Pasteur. Immunol. 139: 569-580

38. Shoenfeld $Y$ (1994) Idiotypic induction of autoimmunity: a new aspect of the idiotypic network. FASEB J. 8: 1296-1301

39. Topfer F, Gordon T and McCluskey J (1995) Intra- and intermolecular spreading of autoimmunity involving the nuclear self-antigens La (SS-B) and Ro (SS-A). Proc. Natl. Acad. Sci. USA 92: 875-879

40. James JA, Gross T, Scofield RH and Harley JB (1995) Immunoglobulin epitope spreading and autoimmune disease after peptide immunization: $\mathrm{Sm} \mathrm{B/B}$ '. derived PPPGMRPP and PPPGIRGP induce spliceosome autoimmunity. J. Exp. Med. 181: 453-461 